\title{
Estradiol supports in vitro development of bovine early antral follicles
}

\author{
M Endo, R Kawahara-Miki ${ }^{1}$, F Cao ${ }^{2}$, K Kimura ${ }^{3}$, T Kuwayama, Y Monji and H Iwata \\ Department of Animal Science, Tokyo University of Agriculture, Funako 1737, Atsugi, Kanagawa 243-0034, Japan, \\ ${ }^{1}$ Genome Research Center, NODAI Research Institute, Tokyo University of Agriculture, Setagaya 156-8502, Japan, \\ ${ }^{2}$ Department of Bioscience, Tokyo University of Agriculture, Setagaya 156-8502, Japan and ${ }^{3}$ National Institute of \\ Livestock and Grassland Science, Tochigi 329-2793, Japan
}

Correspondence should be addressed to H Iwata; Email: h1iwata@nodai.ac.jp

M Endo and R Kawahara-Miki contributed equally to this work

\begin{abstract}
Antrum formation and estradiol $\left(E_{2}\right)$ secretion are specific features of oocyte and granulosa cell complexes (OGCs). This study investigates the effect of $E_{2}$ on the in vitro development of bovine OGCs derived from early antral follicles as well as on the expression of genes in granulosa cells (GCs). The supplementation of culture medium with either $E_{2}$ or androstenedione $\left(A_{4}\right)$ improved the in vitro development of OGCs and the nuclear maturation of enclosed oocytes. When OGCs were cultured in medium containing $A_{4}$, developmentally competent OGCs secreted more $E_{2}$ than OGCs that were not competent. In addition, fulvestrant inhibited the effect of both $E_{2}$ and $A_{4}$ on OGCs development. Comprehensive gene expression analysis using next-generation sequence technology was conducted for the following three types of GCs: i) GCs of OGCs cultured for 4 days with $E_{2}\left(1 \mu \mathrm{g} / \mathrm{ml} ; E_{2}(+)\right)$, ii) GCs of OGCs cultured for 4 days without $E_{2}\left(E_{2}(-)\right)$ or iii) OGCs that formed clear antrum after 8 days of in vitro culture in medium containing $E_{2}(1 \mu \mathrm{g} / \mathrm{ml}$; AF group). GCs of the $E_{2}(+)$ group had a similar gene expression profile to the profile reported previously for the in vivo development of large follicles. This genetic profile included factors implicated in the up-regulation of $E_{2}$ biosynthesis and down-regulation of cytoskeleton and extracellular matrices. In addition, a novel gene expression profile was found in the AF group. In conclusion, $\mathrm{E}_{2}$ impacts the gene expression profile of GCs to support the in vitro development of OGCs.

Reproduction (2013) $\mathbf{1 4 5} 85-96$
\end{abstract}

\section{Introduction}

Granulosa cells (GCs) that are derived from early antral follicles (EAFs) secrete estradiol $\left(E_{2}\right)$ and are involved in antral formation. When oocyte and granulosa cell complexes (OGCs) are collected from bovine EAFs and cultured in vitro, granulosa cells (GCs) form antrallike cavities secrete $E_{2}$ into the culture medium. After $12-16$ days in culture, oocytes grown in vitro acquire full developmental competence (Mingoti et al. 2002, Hirao et al. 2004). The relationship between $E_{2}$ in follicular fluid (FF) or in culture medium and oocyte competence has been reported (Xu et al. 2006, West-Farrell et al. 2009) in mice. However, studies on aromatase KO mice suggest that the significance of $\mathrm{E}_{2}$ on in vivo oocyte development is limited (Huynh et al. 2004). The aromatase $\mathrm{KO}$ mouse has an ovulation defect, but the oocytes were shown to have full developmental competence in vitro. Estrogen receptor $\beta \mathrm{KO}$ mice also have defects in ovulation, differentiation of the GCs and follicle maturation (Couse et al. 2005, Emmen et al.
2005, Drummond 2006). To culture OGCs derived from EAFs in vitro, culture conditions have to maintain and/or develop functions of the GCs; however, the effect of $\mathrm{E}_{2}$ on the in vitro development of OGCs and the functions of the granulosa cells, as well as the molecular basis underling the beneficial effect of $E_{2}$, are not clearly understood.

The aim of this study is to examine the role of $\mathrm{E}_{2}$ during the in vitro development of OGCs by answering the following questions: i) does $E_{2}$ directly improve the in vitro development of OGCs derived from EAFs; ii) does the ability of OGCs to secrete $E_{2}$ relate to the developmental competence of the OGCs and 3) what is the molecular basis associated with the beneficial effect of $E_{2}$ on the growth of OGCs?

\section{Results}

In Experiment 1, the ratio of antral cavity formation was very low at day 4 of the culture period. Subsequently, formation rapidly increased until day 8 (Table 1 ). When 
Table 1 Effect of estradiol in culture medium on development of OGCs.

\begin{tabular}{|c|c|c|c|c|c|c|c|c|c|}
\hline \multirow[b]{2}{*}{$\underline{\mathbf{E}_{2}}(\mu \mathrm{g} / \mathrm{ml})$} & \multirow[b]{2}{*}{ No. of trials } & \multirow[b]{2}{*}{$\begin{array}{l}\text { No. of } \\
\text { OGCs }\end{array}$} & \multicolumn{4}{|c|}{ Rate $(\%)$ of OGCs with antrum, mean \pm s.E.M. } & \multicolumn{2}{|c|}{ Oocyte diameter } & \multirow[b]{2}{*}{$\begin{array}{c}\text { Maturation ratio } \\
\mathrm{M} 2 / \text { total }\end{array}$} \\
\hline & & & 4 Days & 8 Days & 12 Days & 16 Days & $n$ & $\begin{array}{c}\text { Mean } \pm \\
\text { S.E.M. }(\mu \mathrm{m})\end{array}$ & \\
\hline 0 & 10 & 100 & $0.0^{*}$ & $5.0 \pm 2.2 *$ & $6.0 \pm 2.7^{*}$ & $7.0 \pm 3.3^{*}$ & 6 & $115.4 \pm 1.5$ & $0 / 50(0)^{*}$ \\
\hline 0.1 & 10 & 100 & $1.0 \pm 1.0^{*,+}$ & $34.8 \pm 7.1^{\dagger}$ & $37.7 \pm 4.8^{\dagger}$ & $42.7 \pm 5.3^{\dagger}$ & 17 & $118.6 \pm 1.1$ & $6 / 50(12.0)^{\dagger}$ \\
\hline 1 & 10 & 100 & $5.0 \pm 2.2^{*,+}$ & $38.0 \pm 7.3^{+}$ & $41.0 \pm 5.7^{\dagger}$ & $36.0 \pm 6.7^{+}$ & 22 & $117.3 \pm 1.7$ & $13 / 50(26.0)^{\dagger, \ddagger}$ \\
\hline 10 & 10 & 100 & $8.0 \pm 2.5^{\dagger}$ & $49.0 \pm 6.6^{\dagger}$ & $55.0 \pm 4.3^{\dagger}$ & $56.0 \pm 5.8^{\dagger}$ & 31 & $122.2 \pm 1.2$ & $17 / 50(34.0)^{\ddagger}$ \\
\hline
\end{tabular}

${ }_{*,+, \neq} P<0.05$

OGCs were cultured in medium without $E_{2}$ supplementation, the rate of antral cavity formation was $7.0 \%$ and no oocytes reached the M2 stage. Supplementation of the culture medium with $\mathrm{E}_{2}$ improved the cavity formation, and the highest ratio of antrum cavity formation was obtained with the medium containing $10 \mu \mathrm{g} / \mathrm{ml} \mathrm{E}_{2}(56.0 \%)$. The average diameter of the in vitro grown oocytes was $122.2 \mu \mathrm{m}$. When the oocytes grown in vitro were cultured further for $23 \mathrm{~h}, \sim 30.0 \%$ of the oocytes reached M2 stage. Supplementation of the culture medium with 1 and $10 \mu \mathrm{g} / \mathrm{ml} \mathrm{A}_{4}$ improved antrum formation $(26.7 \%)$, and 7.8 and $6.7 \%$ of OGCs reached the M2 stage respectively (Table 2). When OGCs were cultured in medium containing $1 \mu \mathrm{g} / \mathrm{ml} \mathrm{A}_{4}$, the $\mathrm{E}_{2}$ concentration in the medium of competent OGCs was $5.5 \pm 0.9 \mathrm{ng} / \mathrm{ml}$, which was significantly greater than that in un-competent OGCs $(3.1 \pm 0.5 \mathrm{ng} / \mathrm{ml}, P<0.05$; Table 3). When the $A_{4}$ concentration was increased to $10 \mu \mathrm{g} / \mathrm{ml}$ from $1 \mu \mathrm{g} / \mathrm{ml}$, the $E_{2}$ concentration of the competent OGCs was significantly increased to $11.3 \mathrm{ng} / \mathrm{ml}$, which was significantly greater than that of un-competent OGCs $(4.5 \mathrm{ng} / \mathrm{ml}, P<0.05)$ There was a significant interaction observed between $\mathrm{A}_{4}$ concentrations in the culture medium and $E_{2}$ concentrations secreted from OGCs.

Fulvestrant $(1 \mu \mathrm{g} / \mathrm{ml})$ completely inhibited OGC antrum formation of OGCs that were cultured with either $1 \mu \mathrm{g} / \mathrm{ml} \mathrm{A}_{4}$ or $0.1 \mu \mathrm{g} / \mathrm{ml} \mathrm{E}_{2}$. The inhibitory effect of fulvestrant was ameliorated by increasing the concentration of $E_{2}$ from 0.1 to $1 \mu \mathrm{g} / \mathrm{ml}$ (Table 4).

Table 5 lists genes that have been previously reported as markers of follicle cells for the largest follicle in cows (Hayashi et al. 2010). With a few exceptions, many of the genes that are reported to be highly expressed in the largest follicle tend to have their expression enhanced by $\mathrm{E}_{2}$ treatment. The FOS, SCD and FST had slightly but significant low expression ratio in $\mathrm{E}_{2}(+)$ group to those seen in $E_{2}(-)$ group $(-1.22,-1.04$ and -1.04 respectively, $P<0.01)$. When OGCs were cultured for 8 days, expression of FOS further decreased, while expression of $S C D$ and FST increased in the AF group compared with the level observed in the $E_{2}(+)$ group $(P<0.01)$. Conversely, the expressions of many genes that are reported to be highly expressed in the second largest follicle were depressed by $E_{2}$ treatment. Continued in vitro culture showed that the expression of CRABP2 and SERPINE1 increase in the AF group compared with the expression observed in the $E_{2}(+)$ group. Table 6 shows the expression of genes related to steroid biosynthesis, WNT/CTNNTB1 signalling and members of the THBS, VEGF, JUN and FOS families. $H S D 17 B 1$ were significantly up-regulated by $E_{2}$ treatment and antrum formation, whereas CYP11A and HSD3B1 decreased. CYP19A1 increased in $\mathrm{E}_{2}(+)$ and $\mathrm{AF}$ groups (1.35- and 1.78-fold respectively) but the increasing did reach significant due to low RPKM (reads per kilobase of exon per million reads of mapped reads) value. The expression of genes related to WNT2/ CTNNB1 was altered in the $\mathrm{E}_{2}(+)$ and $\mathrm{AF}$ groups (Table 6 and Fig. 1). The relative expression levels in $\mathrm{E}_{2}(+)$ and $\mathrm{E}_{2}(-)$ are shown in Table 6 and were -1.43 , -2.55 and 1.31 for WNT2B, SFRP4 and NR5A1 respectively $(P<0.05)$. The expression of $F Z D 1$ and $F Z D 9$, the receptor of WNT2 and the co-receptor LRP6 were not affected by $E_{2}$ treatment, although the expression of LPR5 slightly but significantly increased. During continued in vitro culture, the expression of FOXO1 significantly decreased $(P<0.01)$ and the genes contained in destruction complex (APC, AXINs, GSK3B, and CSNK1E) tend to decrease (Table 6), and many differentially expressed genes in the AF group were linked to low expression of FOS (Fig. 1). The expression of members of the FOS and JUN families was also significantly low in the $E_{2}(+)$ group compared with the

Table 2 Effect of supplementation of culture medium with androstenedione on development of OGCs.

\begin{tabular}{|c|c|c|c|c|c|c|c|}
\hline \multirow[b]{2}{*}{$\underline{\mathbf{A}_{\mathbf{4}}(\mu \mathrm{g} / \mathrm{ml})}$} & \multirow[b]{2}{*}{ No. of trials } & \multirow[b]{2}{*}{ No. of OGCs } & \multicolumn{4}{|c|}{ Rate $(\%)$ of OGCs with antrum, mean \pm s.E.M. } & \multirow{2}{*}{$\begin{array}{c}\text { No. }(\%) \text { of } \\
\text { oocytes at M2 }\end{array}$} \\
\hline & & & Day 4 & Day 8 & Day 12 & Day 16 & \\
\hline 0 & 9 & 90 & 0 & $5.0 \pm 3.6^{*}$ & $2.5 \pm 1.5^{*}$ & $0^{*}$ & $0 / 90(0)^{*}$ \\
\hline 1 & 9 & 90 & 0 & $22.2 \pm 5.7^{\dagger}$ & $26.7 \pm 6.0^{\dagger}$ & $26.7 \pm 6.7^{+}$ & $7 / 90(7.8)^{+}$ \\
\hline 10 & 9 & 90 & 0 & $28.9 \pm 6.8^{\dagger}$ & $31.1 \pm 7.5^{\dagger}$ & $26.7 \pm 6.7^{+}$ & $6 / 90(6.7)^{+}$ \\
\hline
\end{tabular}

${ }^{*,+} P<0.05$. 
Table 3 Relationship between estradiol secretion and antrum cavity formation of OGCs.

\begin{tabular}{|c|c|c|c|c|}
\hline \multirow[b]{3}{*}{$\begin{array}{l}\text { Antrum } \\
\text { cavity } \\
\text { forma- } \\
\text { tion }\end{array}$} & \multicolumn{4}{|c|}{$\mathbf{A}_{\mathbf{4}}(\mu \mathrm{g} / \mathrm{ml})$} \\
\hline & \multicolumn{2}{|c|}{1} & \multicolumn{2}{|c|}{10} \\
\hline & $\begin{array}{c}\text { No. of } \\
\text { samples } \\
\text { examined }\end{array}$ & $\begin{array}{c}\mathrm{E}_{2} \text { concen- } \\
\text { tration } \\
(\mathrm{ng} / \mathrm{ml}) \\
\text { mean } \pm \text { s.E.M. }\end{array}$ & $\begin{array}{c}\text { No. of } \\
\text { samples } \\
\text { examined }\end{array}$ & $\begin{array}{c}\mathrm{E}_{2} \text { concen- } \\
\text { tration } \\
(\mathrm{ng} / \mathrm{ml}) \\
\text { mean } \pm \text { s.E.M. }\end{array}$ \\
\hline+ & 24 & $5.5 \pm 0.9^{*, \neq}$ & 20 & $11.3 \pm 1.0^{*, \S}$ \\
\hline- & 53 & $3.1 \pm 0.5^{\prime+}$ & 20 & $4.5 \pm 1.2^{\prime}$ \\
\hline
\end{tabular}

${ }_{*, t, \pm, \S} P<0.05$.

$E_{2}(-)$ group (Table 6). A network of genes differentially expressed between the $E_{2}(+)$ and $E_{2}(-)$ conditions are shown in Fig. 2. The expression of THBS1 and THBS2 significantly decreased with $E_{2}$ treatment $(-3.15$ and $-1.96)$, whereas $V E G F B$ increased $(P<0.05)$. This gene expression is linked to low expression of IGFBP3 and 5, $C O L 1 A, F N 1$, and $A M H$. However, the expression of THBS1 was significantly increased in the AF condition compared with the $E_{2}(+)$ group (Table 6). Genes implicated in cardiovascular system development and function were among the genes that most frequently had differential expression in the $\mathrm{E}_{2}(+)$ and $\mathrm{E}_{2}(-)$ conditions (Supplementary Table 1, see section on supplementary data given at the end of this article). Of the TGF $\beta$ family members, TGF $\beta 1$ were down-regulated in the $\mathrm{E}_{2}(+)$ group. Expression of $B M P 1$ slightly but significantly decreased in $E_{2}(+)$ group, the receptor for BMPs (BMPR1B) much decreased in the AF group compared with the expression observed in the $E_{2}(+)$ group (Table 7). The expression of most BMP antagonists decreased in the $E_{2}(+)$ group compared with the $E_{2}(-)$ group, but in AF medium, FST and FSTL3 increased to over 1.5-fold the level observed in the $\mathrm{E}_{2}(+)$ medium $\left(P<0.01\right.$; Table 7). As observed in Figs 3 and $4, E_{2}$ treatment of OGCs tended to decrease the expression of genes related to the cytoskeleton and extracellular matrix $(E C M)$, representing significant low expression of ACTA2 (-2.18), ACTG2 (-2.15), KRT8 (-1.90), COL1A1 (-2.95), COL4A1 (-1.55) and LAMA5 $(-1.46)$ (Supplementary Table 2, see section on supplementary data given at the end of this article); genes related to each function were selected using Kegg (http://www.genome.jp/kegg/brite.html). In addition, the changes in gene expression were very robust in the AF conditions. The functions of the genes that are differentially expressed in the $\mathrm{AF}$ and $\mathrm{E}_{2}(+)$ groups include roles in cancer development, cellular movement, cellular growth and proliferation, apoptosis and cellular differentiation (Supplementary Table 1).

\section{Discussion}

This study shows that endogenous and exogenous $E_{2}$ directly supports the in vitro development of OGCs and, to the best of our knowledge, it is the first to show gene profiles either in GCs of OGCs treated with $E_{2}$ or in those of OGCs that formed antrum in vitro.

This study provides evidence for the following: i) both $E_{2}$ and $A_{4}$ improve the in vitro growth of OGCs, ii) competent OGCs have a greater ability to secrete $E_{2}$ into the culture medium than un-competent OGCs and iii) inhibition of $E_{2}$ prevents both $A_{4}$ and $E_{2}$ from supporting the in vitro development of OGCs. In addition, increasing the $E_{2}$ concentration from 1 to $10 \mu \mathrm{g} / \mathrm{ml}$ ameliorated the inhibitory effect of the inhibitor on OGC development. Taken together, we conclude that endogenous and exogenous $\mathrm{E}_{2}$ maintains or helps to develop the functions of GCs of OGCs cultured in vitro. This finding sheds light on the long disputed question regarding the significance of $E_{2}$ on in vitro follicle development (Walters et al. 2008, Okutsu et al. 2010, Romero \& Smitz 2010, Taketsuru et al. 2011). It is worth noting that the $E_{2}$ concentration used in this study is much greater than that is in blood (Mann \& Lamming 2001). OGCs are enclosed in FF, which contains a high concentration of $E_{2}$ compared with that in blood. We measured the concentration of $E_{2}$ in bovine $F F$ previously and found the highest $E_{2}$ concentration to be about $0.1-0.2 \mu \mathrm{g} / \mathrm{ml}$. In addition, the $E_{2}$ concentration in bovine antral follicles reportedly ranges from 0 to $0.3 \mu \mathrm{g} / \mathrm{ml}$ (Ouellette et al. 2005, Monniaux et al. 2008, Nishimoto et al. 2009, Green et al. 2011). Furthermore, Bridges et al. (2005) reported that when bovine follicle cells were cultured in vitro, the concentration of $E_{2}$ secreted was $0.2 \mu \mathrm{g} / \mathrm{ml}$. The concentration of $E_{2}$ used in this study is $1 \mu \mathrm{g} / \mathrm{ml}$, which is still higher than that found in antral FF. Because the concentration is measured using well-mixed FFs, it is plausible that the concentration of $\mathrm{E}_{2}$ proximal to the GC

Table 4 Effect of fulvestrant on the effects of $E_{2}$ and $A_{4}$ on development of OGCs.

\begin{tabular}{|c|c|c|c|c|c|c|}
\hline & \multirow[b]{2}{*}{ No. of trials } & \multirow[b]{2}{*}{ No. of OGCs } & \multicolumn{4}{|c|}{ Rate $(\%)$ of OGCs with antrum, mean \pm S.E.M. } \\
\hline & & & Day 4 & Day 8 & Day 12 & Day 16 \\
\hline $1 \mu \mathrm{g} / \mathrm{ml} \mathrm{A}_{4}$ & 10 & 100 & $0.0 \pm 0.0$ & $20.0 \pm 4.4^{*}$ & $28.0 \pm 6.1^{*}$ & $24.0 \pm 4.7^{*}$ \\
\hline $1 \mu \mathrm{g} / \mathrm{ml} \mathrm{A}_{4}+$ fulvestrant & 10 & 100 & $0.0 \pm 0.0$ & $0.0 \pm 0.0^{\dagger}$ & $0.0 \pm 0.0^{\dagger}$ & $0.0 \pm 0.0^{+}$ \\
\hline $0.1 \mu \mathrm{g} / \mathrm{ml} \mathrm{E}_{2}$ & 10 & 100 & $0.0 \pm 0.0$ & $17.0 \pm 6.0$ & $21.0 \pm 5.7^{*}$ & $18.0 \pm 6.1^{*}$ \\
\hline $0.1 \mu \mathrm{g} / \mathrm{ml} \mathrm{E}_{2}+$ fulvestrant & 10 & 100 & $0.0 \pm 0.0$ & $10.0 \pm 4.2$ & $4.0 \pm 3.1^{+}$ & $0.0 \pm 0.0^{+}$ \\
\hline $1 \mu \mathrm{g} / \mathrm{ml} \mathrm{E} \mathrm{E}_{2}$ & 10 & 100 & $3.0 \pm 1.5$ & $42.0 \pm 4.4$ & $46.0 \pm 4.8$ & $34.0 \pm 4.0$ \\
\hline $1 \mu \mathrm{g} / \mathrm{ml} \mathrm{E}_{2}+$ fulvestrant & 10 & 100 & $1.0 \pm 1.0$ & $29.0 \pm 5.7$ & $35.0 \pm 6.2$ & $28.0 \pm 6.1$ \\
\hline
\end{tabular}

${ }^{*,+} P<0.05$. 
Table 5 Expression of marker genes in granulosa cells.

\begin{tabular}{|c|c|c|c|c|c|c|c|c|c|}
\hline \multirow{2}{*}{$\begin{array}{l}\text { Marker genes, } \\
\text { Hayashi et al. (2010) }\end{array}$} & \multicolumn{3}{|c|}{ RPKM value } & \multicolumn{6}{|c|}{ Ratio $^{a}$} \\
\hline & $\mathrm{E}_{2}(+)$ & $\mathrm{AF}$ & $\mathrm{E}_{2}(-)$ & $\mathrm{E}_{2}(+) / \mathrm{E}_{2}(-)$ & $P$ value* & $\mathrm{AF} / \mathrm{E}_{2}(+)$ & $P$ value & $\mathrm{AF} / \mathrm{E}_{2}(-)$ & $P$ value \\
\hline \multicolumn{10}{|l|}{ Largest } \\
\hline FOS & 33.85 & 17.73 & 41.13 & -1.22 & 0.001 & -1.91 & 0.026 & -2.32 & 0.000 \\
\hline$R G N$ & 7.28 & 3.88 & 8.33 & -1.14 & 0.178 & -1.87 & 0.381 & -2.15 & 0.030 \\
\hline$S C D$ & 1010.82 & 1335.50 & 1052.84 & -1.04 & 0.000 & 1.32 & 0.000 & 1.27 & 0.000 \\
\hline FST & 775.87 & 1359.46 & 805.32 & -1.04 & 0.000 & 1.75 & 0.000 & 1.69 & 0.014 \\
\hline TNFAIP8 & 1.50 & 2.10 & 1.51 & -1.01 & 0.618 & 1.41 & 1.000 & 1.39 & 0.613 \\
\hline$S R G N$ & 5735.20 & 9677.05 & 5717.45 & 1.00 & 0.000 & 1.69 & 0.000 & 1.69 & 0.000 \\
\hline PIGF & 15.69 & 17.61 & 14.75 & 1.06 & 0.136 & 1.12 & 0.865 & 1.19 & 0.203 \\
\hline GUCA1A & 4.24 & 18.61 & 3.61 & 1.18 & 0.465 & 4.39 & 0.003 & 5.16 & 0.123 \\
\hline$A M H$ & 85.01 & 106.06 & 71.91 & 1.18 & 0.007 & 1.25 & 0.219 & 1.47 & 0.115 \\
\hline SERPINF2 & 2.37 & 3.17 & 1.98 & 1.20 & 0.618 & 1.34 & 1.000 & 1.60 & 1.000 \\
\hline GCLC & 365.31 & 411.73 & 298.41 & 1.22 & 0.000 & 1.13 & 0.223 & 1.38 & 0.000 \\
\hline SLC 39A14 & 44.02 & 55.03 & 35.50 & 1.24 & 0.079 & 1.25 & 0.367 & 1.55 & 0.324 \\
\hline PLA2G1B & 3.86 & 4.21 & 3.04 & 1.27 & 0.704 & 1.09 & 1.000 & 1.39 & 0.700 \\
\hline INHBA & 77.57 & 212.50 & 59.67 & 1.30 & 0.050 & 2.74 & 0.000 & 3.56 & 0.000 \\
\hline INHA & 875.33 & 1917.79 & 655.32 & 1.34 & 0.000 & 2.19 & 0.000 & 2.93 & 0.000 \\
\hline HSD $17 B 1$ & 348.75 & 554.18 & 267.63 & 1.30 & 0.000 & 1.59 & 0.000 & 2.07 & 0.227 \\
\hline CITED1 & 16.01 & 17.76 & 11.88 & 1.35 & 0.432 & 1.11 & 0.865 & 1.49 & 0.567 \\
\hline CYP19A1 & 12.26 & 21.84 & 9.08 & 1.35 & 0.498 & 1.78 & 0.123 & 2.41 & 0.576 \\
\hline FSHR & 41.57 & 48.34 & 30.01 & 1.39 & 0.269 & 1.16 & 0.674 & 1.61 & 0.477 \\
\hline TMEM2O & 15.01 & 15.43 & 9.14 & 1.64 & 0.833 & 1.03 & 1.000 & 1.69 & 0.831 \\
\hline IGFBP2 & 71.45 & 28.27 & 38.28 & 1.87 & 1.000 & -2.53 & 0.000 & -1.35 & 0.000 \\
\hline$G P X 3$ & 38.78 & 20.32 & 16.52 & 2.35 & 0.487 & -1.91 & 0.013 & 1.23 & 0.167 \\
\hline \multicolumn{10}{|l|}{ Second largest } \\
\hline ADAMTS1 & 9.43 & 2.90 & 19.20 & -2.04 & 0.001 & -3.25 & 0.088 & -6.62 & 0.000 \\
\hline CCDC80 & 28.57 & 30.52 & 60.16 & -2.11 & 0.000 & 1.07 & 0.898 & -1.97 & 0.000 \\
\hline$C R A B P 2$ & 756.06 & 1100.79 & 1121.66 & -1.48 & 0.000 & 1.46 & 0.000 & -1.02 & 0.000 \\
\hline GADD45A & 24.36 & 13.35 & 24.33 & 1.00 & 0.048 & -1.83 & 0.070 & -1.82 & 0.000 \\
\hline IGFBP5 & 77.42 & 8.36 & 134.50 & -1.74 & 0.000 & -9.27 & 0.000 & -16.10 & 0.000 \\
\hline KRT8 & 89.70 & 60.65 & 170.78 & -1.90 & 0.000 & -1.48 & 0.012 & -2.82 & 0.000 \\
\hline LOXL4 & 6.87 & 2.64 & 29.38 & -4.28 & 0.000 & -2.60 & 0.220 & -11.13 & 0.000 \\
\hline OLR1 & 6.16 & 2.34 & 21.21 & -3.44 & 0.000 & -2.63 & 0.173 & -9.06 & 0.000 \\
\hline$O X T$ & 57.23 & 3.52 & 91.62 & -1.60 & 0.000 & -16.27 & 0.000 & -26.05 & 0.000 \\
\hline PDK4 & 6.46 & 2.65 & 6.52 & -1.01 & 0.244 & -2.44 & 0.337 & -2.46 & 0.039 \\
\hline PLAUR & 5.82 & 1.53 & 15.88 & -2.73 & 0.000 & -3.80 & 0.173 & -10.39 & 0.000 \\
\hline SERPINE1 & 59.93 & 164.47 & 179.08 & -2.99 & 0.000 & 2.74 & 0.000 & -1.09 & 0.000 \\
\hline SFRP4 & 6.71 & 9.77 & 17.10 & -2.55 & 0.000 & 1.45 & 0.630 & -1.75 & 0.004 \\
\hline SLC1A5 & 11.73 & 10.73 & 11.65 & 1.01 & 0.140 & -1.09 & 0.837 & -1.09 & 0.083 \\
\hline THBS2 & 54.13 & 9.15 & 106.00 & -1.96 & 0.000 & -5.92 & 0.000 & -11.59 & 0.000 \\
\hline TIMP1 & 181.46 & 14.30 & 251.89 & -1.39 & 0.000 & -12.69 & 0.000 & -17.62 & 0.000 \\
\hline
\end{tabular}

* $P$ values are calculated by Fisher's exact test.

${ }^{a} W$ hen the ratio is $<1$, it is converted to its negative inverse.

is higher than that of mixed FF. Considering these findings and this possibility, I concluded that 0.1 or $1 \mu \mathrm{g} / \mathrm{ml}$ of $E_{2}$ is relevant to yield full-grown oocytes in vitro. However, in the current culture system, it remains unclear why the low concentration of $E_{2}$ does not support antrum formation. Thus far, there have been reports showing the relationship of the robust developmental ability of mouse OGCs with either high concentrations of $E_{2}$ secreted from GCs or high Cyp19a1 expression in GCs (Xu et al. 2006, West-Farrell et al. 2009). In addition, studies on KO mice suggest that $\mathrm{E}_{2}$ mainly affects follicle maturation and ovulation including GC function (Couse et al. 2005, Drummond 2006). In this context, we examined comprehensive gene expression of $E_{2}(-), E_{2}(+)$ and $A F$ GCs.

Our first question was whether the OGCs cultured in the in vitro medium containing $\mathrm{E}_{2}$ develop normally? In this study, we compared the expression of genes in GCs of OGCs developed in vitro with the expression of previously reported marker genes related to GCs from in vivo developed, healthy, large follicles in cows (Hayashi et al. 2010). In the report, the expression of several marker genes was compared between GCs of the largest follicle and the second largest follicles. Upon comparing our data with the reported results, many results are consistent, genes highly expressed in the largest follicle are highly expressed in $\mathrm{E}_{2}(+)$ compared with those observed in $\mathrm{E}_{2}(-)$. With continued in vitro culture, the expression of many parts of these genes is enhanced in the AF group. In addition, ITGA6, THBS1, THBS2, VEGF, AMH, FST and INHBA were reported to express high in growing follicles (Le Bellego et al. 2002, Nilsson et al. 2003, Greenaway et al. 2005, Tesfaye et al. 2009, Rosales-Torres et al. 2010, Bonnet et al. 2011) and 
Table 6 Expression of genes related to steroidogenesis, WNT/CTNNB1 signalling, THBSs, VEGFs, JUNs and FOSs.

\begin{tabular}{|c|c|c|c|c|c|c|c|c|c|}
\hline \multirow[b]{2}{*}{ Gene symbol } & \multicolumn{3}{|c|}{ RPKM value } & \multicolumn{6}{|c|}{ Ratio $^{a}$} \\
\hline & $E_{2}(+)$ & $\mathrm{AF}$ & $\mathrm{E}_{2}(-)$ & $\mathrm{E}_{2}(+) / \mathrm{E}_{2}(-)$ & $P$ value* & $\mathrm{AF} / \mathrm{E}_{2}(+)$ & $P$ value & $\mathrm{AF} / \mathrm{E}_{2}(-)$ & $P$ value \\
\hline CYP11A1 & 53.62 & 24.17 & 68.62 & -1.28 & 0.000 & -2.22 & 0.000 & -2.84 & 0.000 \\
\hline CYP19A1 & 12.26 & 21.84 & 9.08 & 1.35 & 0.498 & 1.78 & 0.123 & 2.41 & 0.576 \\
\hline HSD3B1 & 25.24 & 12.58 & 37.01 & -1.47 & 0.000 & -2.01 & 0.051 & -2.94 & 0.000 \\
\hline HSD17B1 & 348.75 & 554.18 & 267.63 & 1.30 & 0.000 & 1.59 & 0.000 & 2.07 & 0.227 \\
\hline WNT2B & 38.91 & 63.54 & 55.46 & -1.43 & 0.000 & 1.63 & 0.023 & 1.15 & 0.009 \\
\hline SFRP4 & 6.71 & 9.77 & 17.10 & -2.55 & 0.000 & 1.45 & 0.630 & -1.75 & 0.004 \\
\hline FZD1 & 9.26 & 6.97 & 10.02 & -1.08 & 0.149 & -1.33 & 0.624 & -1.44 & 0.043 \\
\hline FZD3 & 16.17 & 16.56 & 15.41 & 1.05 & 0.136 & 1.02 & 1.000 & 1.07 & 0.192 \\
\hline FZD9 & 8.08 & 7.69 & 6.47 & 1.25 & 0.583 & -1.05 & 1.000 & 1.19 & 0.578 \\
\hline LRP5 & 51.30 & 30.26 & 47.47 & 1.08 & 0.011 & -1.70 & 0.014 & -1.57 & 0.000 \\
\hline$L R P 6$ & 13.35 & 10.05 & 12.20 & 1.09 & 0.211 & -1.33 & 0.536 & -1.21 & 0.070 \\
\hline APC & 12.07 & 9.13 & 11.86 & 1.02 & 0.140 & -1.30 & 0.518 & -1.30 & 0.038 \\
\hline AXIN1 & 18.03 & 17.03 & 17.82 & 1.01 & 0.081 & -1.06 & 0.866 & -1.05 & 0.049 \\
\hline AXIN2 & 5.78 & 3.43 & 7.85 & -1.36 & 0.099 & -1.69 & 0.337 & -2.29 & 0.021 \\
\hline CSNK1E & 8.15 & 5.13 & 9.33 & -1.14 & 0.136 & -1.59 & 0.417 & -1.82 & 0.025 \\
\hline GSK3B & 21.04 & 18.42 & 19.78 & 1.06 & 0.101 & -1.14 & 0.632 & -1.07 & 0.026 \\
\hline CTNNB1 & 375.27 & 503.82 & 382.68 & -1.02 & 0.000 & 1.34 & 0.000 & 1.32 & 0.000 \\
\hline FOXO1 & 54.28 & 31.08 & 52.43 & 1.04 & 0.004 & -1.75 & 0.009 & -1.69 & 0.000 \\
\hline NR5A1 & 91.98 & 99.01 & 70.27 & 1.31 & 0.040 & 1.08 & 0.828 & 1.41 & 0.075 \\
\hline THBS1 & 22.00 & 59.76 & 69.34 & -3.15 & 0.000 & 2.72 & 0.000 & -1.16 & 0.000 \\
\hline THBS2 & 54.13 & 9.15 & 106.00 & -1.96 & 0.000 & -5.92 & 0.000 & -11.59 & 0.000 \\
\hline THBS3 & 6.14 & 5.12 & 7.06 & -1.15 & 0.244 & -1.20 & 0.771 & -1.38 & 0.125 \\
\hline VEGFA & 93.18 & 337.51 & 63.38 & 1.47 & 0.209 & 3.62 & 0.000 & 5.32 & 0.000 \\
\hline VEGFB & 38.54 & 39.20 & 36.03 & 1.07 & 0.029 & 1.02 & 0.910 & 1.09 & 0.020 \\
\hline JUN & 37.93 & 28.18 & 52.07 & -1.37 & 0.000 & -1.35 & 0.178 & -1.85 & 0.000 \\
\hline JUNB & 23.96 & 10.35 & 32.39 & -1.35 & 0.001 & -2.32 & 0.015 & -3.13 & 0.000 \\
\hline JUND & 63.25 & 83.02 & 73.53 & -1.16 & 0.000 & 1.31 & 0.159 & 1.13 & 0.001 \\
\hline FOS & 33.85 & 17.73 & 41.13 & -1.22 & 0.001 & -1.91 & 0.026 & -2.32 & 0.000 \\
\hline FOSL1 & 4.25 & 6.78 & 7.88 & -1.85 & 0.033 & 1.59 & 0.549 & -1.16 & 0.173 \\
\hline FOSL2 & 41.43 & 8.31 & 43.62 & -1.05 & 0.002 & -4.99 & 0.000 & -5.25 & 0.000 \\
\hline PPARG & 63.62 & 101.22 & 62.66 & 1.02 & 0.001 & 1.59 & 0.008 & 1.62 & 0.325 \\
\hline$A H R$ & 3.32 & 3.91 & 5.59 & -1.68 & 0.076 & 1.18 & 1.000 & -1.43 & 0.105 \\
\hline
\end{tabular}

* $P$ values are calculated by Fisher's exact test.

${ }^{\mathrm{a}} \mathrm{W}$ hen the ratio is $<1$, it is converted to its negative inverse.

the expression of these genes express high in $E_{2}(+)$ compared with those observed in $\mathrm{E}_{2}(-)$. These results suggest that $E_{2}$ treatment induces OGCs to develop in vitro and that OGCs having antrum after 8 days of in vitro culture are on the way to normal follicle development. However, there were several genes that were exceptions to this trend, which indicates that OGCs may be slightly diverted from normal development; thus, we should look at these genes carefully. These genes were CTGF, CRABP2, FOS, GPX3, GREM1, IGFBP2, NOG and SERPINE1, etc.

West-Farrell et al. (2009) cultured mouse OGCs derived from EAFs in vitro using optimal and suboptimal culture conditions, OGCs cultured in optimal condition secrete more $E_{2}$ and had specific gene expression pattern that included high Cyp19a1 expression and low Cyp11a and $H s d 3 b$ expression. In agreement with this report, CYP19A1 and HSD17B1 were up-regulated by $\mathrm{E}_{2}$ treatment and antrum formation, whereas CYP11A1 and HSD3B1 were down-regulated. In addition, competent OGCs secreted more $E_{2}$ than un-competent OGCs. These results suggest that $E_{2}$ secretion is closely related to OGCs developmental competence and that $E_{2}$ itself induces OGCs to secrete $E_{2}$.
WNT/CTNNB1 is one of the three signalling WNT factors, and it reportedly regulates CYP19A1 expression (Parakh et al. 2006, Boyer et al. 2010). The expression of Wnt2 is high in healthy mouse follicles compared with that of atretic follicles, and both WNT2 and CTNNB1 induce the DNA synthesis of the GCs and prevent these cells from undergoing apoptosis (Wang et al. 2010). Figure 5 summarises the genes related to WNT2/ CTNNB1 signalling and CYP19A1 expression (details were presented in Boyer et al. (2010)). SFRP4 binds to WNT2/4, preventing the WNTs from binding to the receptor FZDs. $E_{2}$ treatment decreased the expression of SFRP4 to a relative level of $39 \%$ of the $E_{2}(-)$ group $(P<0.01$; Table 6$)$. FOXO1A binds to CTNNB1 to inhibit it, and the level of FOXO1 expression in the AF group is $57 \%$ of the $\mathrm{E}_{2}(+)(P<0.0 .1)$. APC, AXIN, CSNK1E and GSK3B are major components of the $\beta$-catenin destruction complex (Kimelman \& Xu 2006), and expression of these factors tended to decrease in the $E_{2}(+)$ and $A F$ conditions. NR5A1 cooperates with CTNNB1 to regulate CYP19A1 expression, and expression of the NR5A1 was significantly high $(P<0.05,1.31$; Table 6$)$ in the $E_{2}(+)$ group compared with that observed in the $E_{2}(-)$ group. In addition, expression of $C T N N B 1$ itself increased in the 


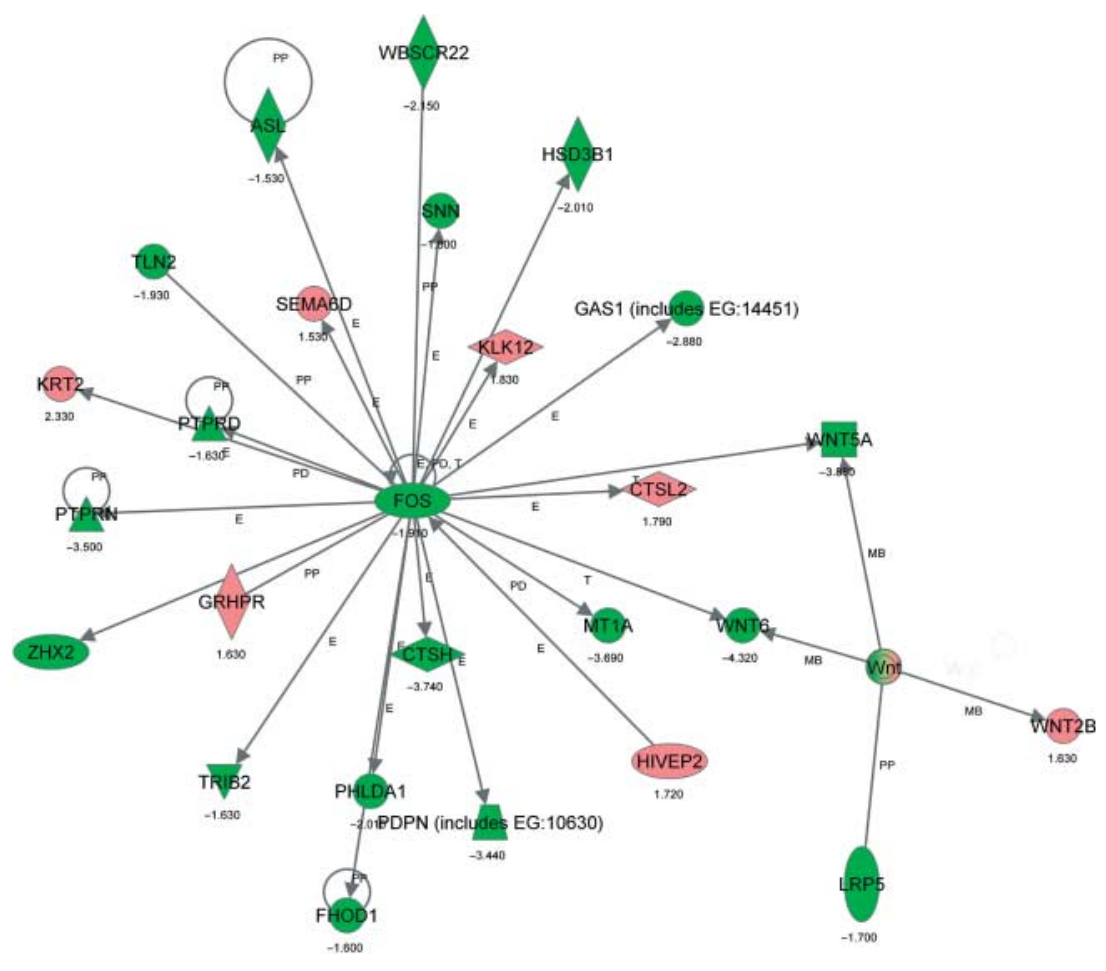

Figure 1 The network of genes showing different levels of expression between the $\mathrm{AF}$ and $\mathrm{E}_{2}(+)$ groups. The functions of the molecules in the network are largely those related to the skeletal and muscular system development and function. The red-coloured symbols represent genes that are up-regulated in the AF group, and the greencoloured symbols represent those that were downregulated. The number under each molecule indicates the ratio of the expression level in the AF group to that in the $\mathrm{E}_{2}(+)$ group. $\mathrm{PP}$, proteinprotein binding; $\mathrm{PD}$, protein-DNA binding; $\mathrm{RE}$, reaction; $M B$, group/complex membership; A, activation; E, expression (includes metabolism/ synthesis for chemicals); $\mathrm{T}$, transcription;

$\mathrm{TR}$, translocation.
AF group $(P<0.01)$. These results suggest that WNT/ CTNNB1 signalling has a role in the $E_{2}$ biosynthesis from OGCs cultured in medium containing $\mathrm{E}_{2}$. In addition, we used gene cards (http://www.genecards.org/) to select transcriptional factors $(A H R, N F K B 1, P P A R G, E 2 F 1$, $E 2 F 2, E 2 F 3, E 2 F 4, F O S, J U N$ and ATF2) that bind to the promoter region of WNT2B and CYP19A1. $\mathrm{E}_{2}$ treatment significantly reduced the expression of member of $J U N$ and $F O S$, and $A H R$, but increased PPARG, expression of $P R A R G$ also increased in $\mathrm{AF}$ group, these changes may be involved in the kinetics of WNT2B and CYP19A1. In addition, CTNNB1 colocalised with $\mathrm{CDH} 1$ (Wang

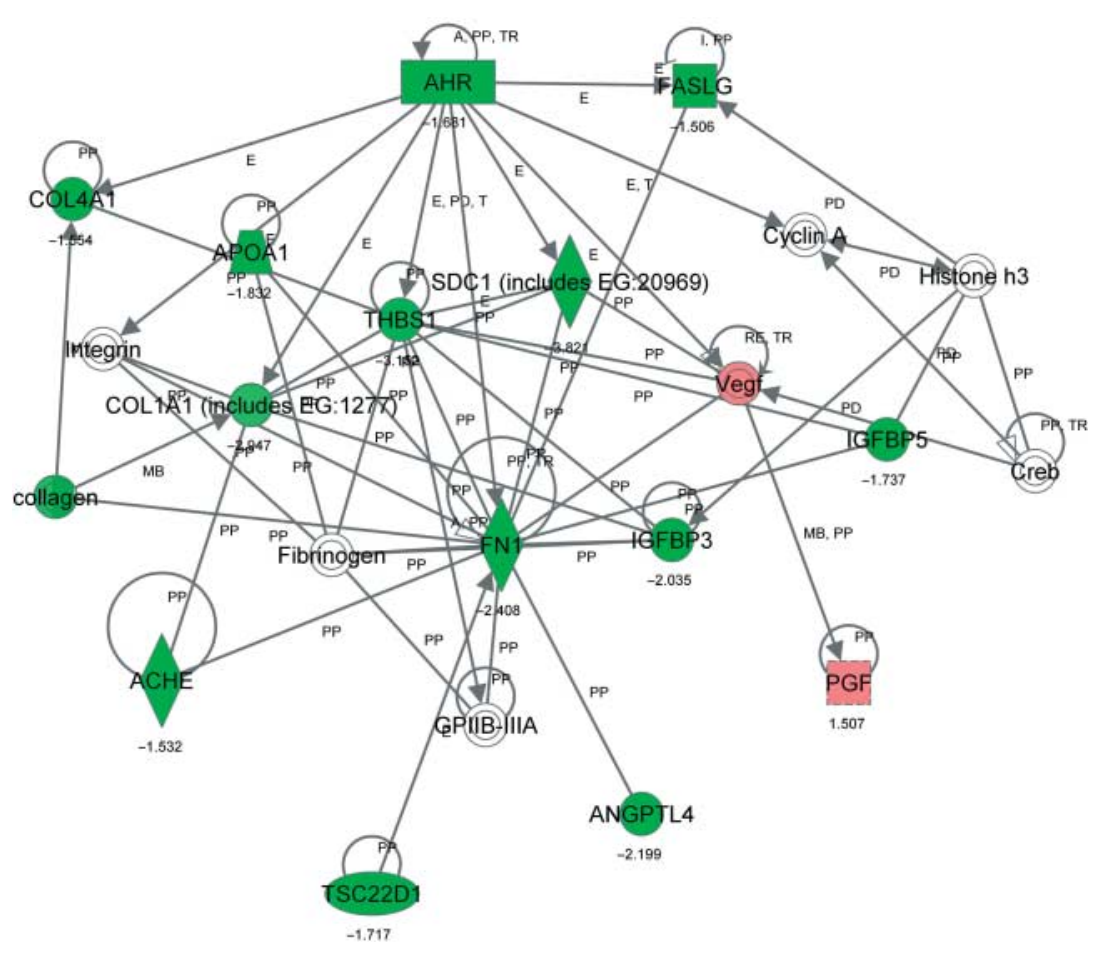

Figure 2 The network of genes with different expression patterns in the $\mathrm{E}_{2}(+)$ and $\mathrm{E}_{2}(-)$ groups. The functions of the molecules in the network are largely those related to cancer, gastrointestinal disease and cardiovascular system development and function. The red-coloured symbols represent genes up-regulated in the $E_{2}(+)$ group, and the green-coloured symbols represent those that were down-regulated. The number under each molecule indicates the ratio of the expression level in the $\mathrm{E}_{2}(+)$ group to that in the $\mathrm{E}_{2}(-)$ group. $\mathrm{PP}$, protein-protein binding; $\mathrm{PD}$, protein-DNA binding; RE, reaction; $M B$, group/complex membership; A, activation; $E$, expression (includes metabolism/synthesis for chemicals); $\mathrm{T}$, transcription; TR, translocation. 
Table 7 Expression of genes related to TGFB family and BMPs and BNP antagonists.

\begin{tabular}{|c|c|c|c|c|c|c|c|c|c|}
\hline \multirow[b]{2}{*}{ Gene symbol } & \multicolumn{3}{|c|}{ RPKM value } & \multicolumn{6}{|c|}{ Ratio $^{a}$} \\
\hline & $E_{2}(+)$ & $\mathrm{AF}$ & $\mathrm{E}_{2}(-)$ & $\mathrm{E}_{2}(+) / \mathrm{E}_{2}(-)$ & $P$ value* & $\mathrm{AF} / \mathrm{E}_{2}(+)$ & $P$ value & $\mathrm{AF} / \mathrm{E}_{2}(-)$ & $P$ value \\
\hline$A C V R 1$ & 4.23 & 2.80 & 5.42 & -1.28 & 0.295 & -1.51 & 0.722 & -1.93 & 0.135 \\
\hline$A C V R 1 B$ & 7.66 & 6.96 & 7.33 & 1.04 & 0.420 & -1.10 & 0.801 & -1.05 & 0.264 \\
\hline$A C V R 2 A$ & 3.45 & 2.43 & 3.30 & 1.05 & 0.433 & -1.42 & 0.683 & -1.36 & 0.349 \\
\hline$A C V R 2 B$ & 5.50 & 3.90 & 5.15 & 1.07 & 0.535 & -1.41 & 0.543 & -1.32 & 0.291 \\
\hline TGFB1 & 9.91 & 2.06 & 17.44 & -1.76 & 0.004 & -4.82 & 0.021 & -8.48 & 0.000 \\
\hline TGFB1/1 & 3.76 & 2.74 & 4.92 & -1.31 & 0.295 & -1.37 & 0.722 & -1.80 & 0.135 \\
\hline TGFBR1 & 21.09 & 19.94 & 19.74 & 1.07 & 0.101 & -1.06 & 0.876 & 1.01 & 0.047 \\
\hline TGFBR2 & 2.01 & 1.04 & 3.75 & -1.87 & 0.194 & -1.94 & 0.619 & -3.62 & 0.052 \\
\hline TGFBR3 & 6.88 & 5.59 & 5.35 & 1.29 & 0.764 & -1.23 & 0.788 & 1.04 & 0.530 \\
\hline TGFBRAP1 & 7.48 & 6.45 & 7.72 & -1.03 & 0.178 & -1.16 & 0.788 & -1.20 & 0.093 \\
\hline$B M P 1$ & 78.34 & 74.74 & 83.13 & -1.06 & 0.000 & -1.05 & 0.687 & -1.11 & 0.000 \\
\hline BMP6 & 7.31 & 9.14 & 7.60 & -1.04 & 0.178 & 1.25 & 0.804 & 1.20 & 0.312 \\
\hline BMPR1A & 12.78 & 11.27 & 11.52 & 1.11 & 0.211 & -1.13 & 0.686 & -1.02 & 0.083 \\
\hline$B M P R 1 B$ & 33.87 & 12.12 & 32.42 & 1.04 & 0.029 & -2.80 & 0.001 & -2.68 & 0.000 \\
\hline BMPR2 & 11.20 & 9.39 & 10.67 & 1.05 & 0.181 & -1.19 & 0.659 & -1.14 & 0.063 \\
\hline$A M H$ & 85.01 & 106.06 & 71.91 & 1.18 & 0.007 & 1.25 & 0.219 & 1.47 & 0.115 \\
\hline INHBA & 77.57 & 212.50 & 59.67 & 1.30 & 0.050 & 2.74 & 0.000 & 3.56 & 0.000 \\
\hline INHA & 875.33 & 1917.79 & 655.32 & 1.34 & 0.000 & 2.19 & 0.000 & 2.93 & 0.000 \\
\hline TWSG1 & 46.86 & 62.89 & 40.21 & 1.17 & 0.043 & 1.34 & 0.183 & 1.56 & 0.408 \\
\hline HTRA1 & 138.71 & 120.91 & 148.27 & -1.07 & 0.000 & -1.15 & 0.173 & -1.23 & 0.000 \\
\hline$N B L 1$ & 9.75 & 21.83 & 11.09 & -1.14 & 0.113 & 2.24 & 0.051 & 1.97 & 1.000 \\
\hline FST & 775.87 & 1359.46 & 805.32 & -1.04 & 0.000 & 1.75 & 0.000 & 1.69 & 0.138 \\
\hline FSTL3 & 46.15 & 74.13 & 65.33 & -1.42 & 0.000 & 1.61 & 0.018 & 1.13 & 0.003 \\
\hline CTGF & 16.32 & 1.99 & 33.69 & -2.06 & 0.000 & -8.21 & 0.001 & -16.94 & 0.000 \\
\hline$C H R D$ & 3.51 & 6.63 & 4.62 & -1.32 & 0.295 & 1.89 & 0.549 & 1.43 & 0.763 \\
\hline$N O G$ & 7.65 & 2.84 & 9.78 & -1.28 & 0.086 & -2.70 & 0.140 & -3.45 & 0.002 \\
\hline GREM1 & 123.67 & 73.32 & 133.89 & -1.08 & 0.000 & -1.69 & 0.000 & -1.83 & 0.000 \\
\hline
\end{tabular}

* $P$ values are calculated by Fisher's exact test.

${ }^{a} W h e n$ the ratio is $<1$, it is converted to its negative inverse.

et al. 2009), and the expression of both CTNNB1 and $\mathrm{CDH} 1$ tend to increase in the $\mathrm{AF}$ group compared with the $E_{2}(+)$ group (1.31 and 1.39 respectively, Supplementary Table 2). The presence of other factors regulating CYP19A1 expression in the $\mathrm{E}_{2}(+)$ group and the other functions of CTNNB1 need to be explored.

Of specific networks of genes differentially expressed between the $E_{2}(+)$ and $E_{2}(-)$ groups, one of the most prominent functions affected by $E_{2}$ treatment-induced expression modifications is angiogenesis (Supplementary Table 1 and Fig. 2). In small antral follicles, where expression of VEGF is low, THBS1 and THBS2 prevent GCs from performing angiogenesis (Garside et al. 2010). As the follicle develops, THBS1 and THBS2 decrease and VEGF increases (Greenaway et al. 2005). Our results agree with these previous observations. However, the expression of THBS1 increased in the AF group, which also indicates that an abnormal event may occur within follicles that are cultured for long period in vitro.

Oocyte and follicle growth is regulated by wellorchestrated interactions among oocytes, GCs and thecal cells. The TGF $\beta$ superfamily, KIT and KITL are major players in these interactions (Knight \& Glister 2006). The TGF $\beta$ superfamily contains BMPs, $\mathrm{AMH}$, activins, inhibins and GDF9, and BMP15 and GDF9 are wellstudied oocyte secretion factors. In this study, the expression of $B M P 1$ was high throughout in vitro culture period and was lightly but significantly affected by $E_{2}$ treatment. The functions of various BMPs depend on many BMP antagonists, which are expressed in GCs (Fenwick et al. 2011). We detected expression of TWSG1, HTRA1, NBL1, FST, FSTL3, CTGF, CHRD, NOG and GREM1. The expression of these genes is reduced in the $E_{2}(+)$ group compared with the $E_{2}(-)$ group, indicating that $\mathrm{E}_{2}$ treatment impacts $\mathrm{GC}$-oocyte interactions. Once OGCs formed antrum, some of these antagonists increased or decreased over twofold. Our results show that in order to form antrum, each antagonist has a unique contribution and relies on complex mutual interactions. The expression of CTGF is depressed by $E_{2}$ treatment and antrum formation to the extent that the relative expression level in the $\mathrm{AF}$ group to that of the $\mathrm{E}_{2}(-)$ group is $6 \%(P<0.01)$. Conversely (Harlow et al. 2007), it has been reported that the expression of CTGF and CYP19A1 increases as follicles develop in rats. Studies with Ctgf conditional KO mice have reported that expression of $C \operatorname{tg} f$ is also necessary for follicle development (Nagashima et al. 2011). These mice also show a decline in the expression of $M y c$, Adamts 1 and an increase in the expression of Hsd3b1, Hsd17b7, Sfrp4, and Kitl. In this study, while expression of CTGF was decreased following $\mathrm{E}_{2}$ treatment and antrum formation, ADAMTS1 also significantly decreased (Table 5), which agrees with the report. However, KITL and HSD3B1 in the AF group tended to decrease to 40 and $50 \%$ of the levels observed in $E_{2}(+)$ 


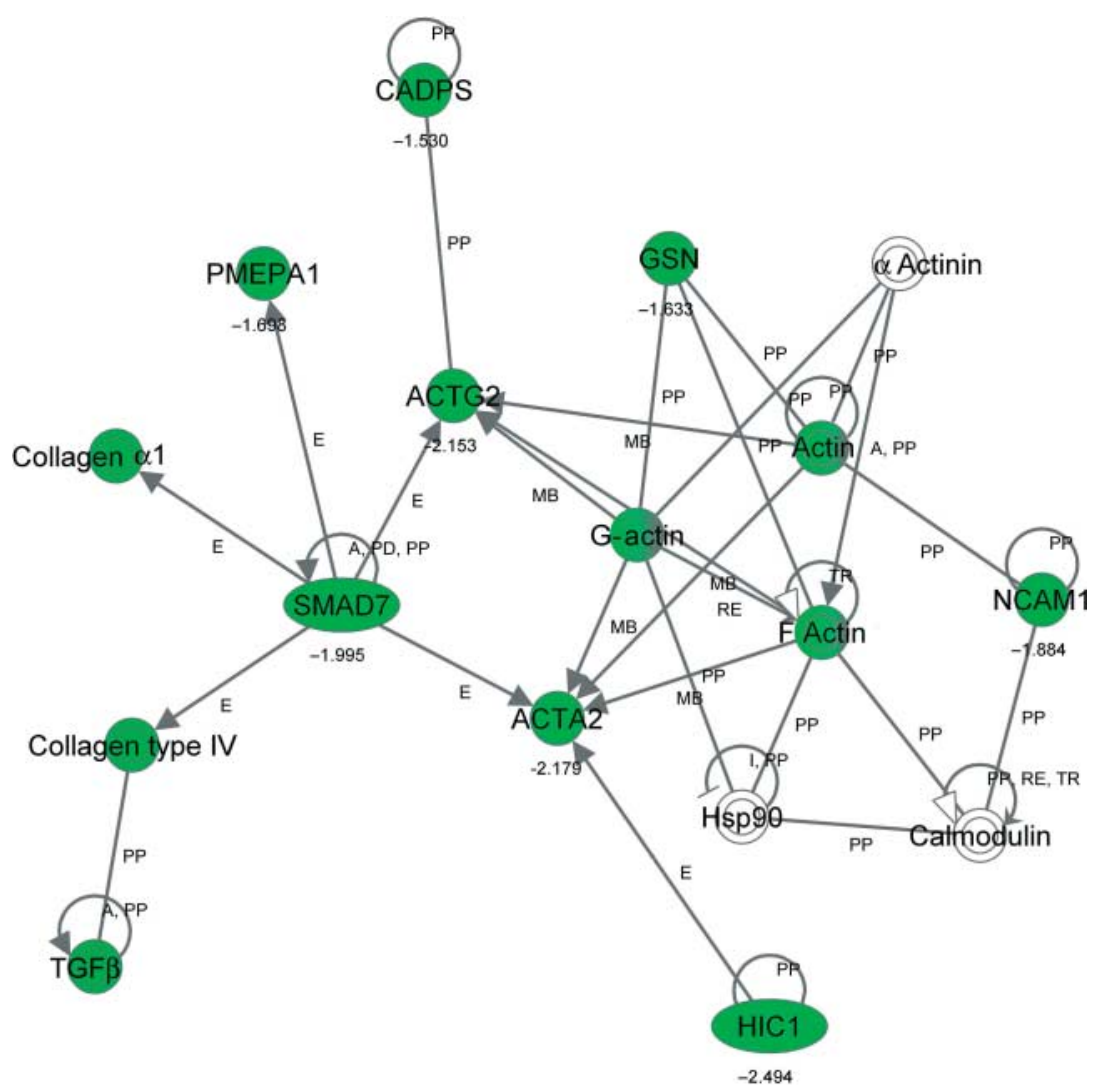

Figure 3 The network of genes with differential expression between the $E_{2}(+)$ and $E_{2}(-)$ groups. The functions of the molecules in the network are largely those related to cell-to-cell signalling and interaction, cellular assembly and organisation and cellular movement. PP, protein-protein binding; PD, protein-DNA binding; RE, reaction; $M B$, group/complex membership; $A$, activation; $E$, expression (includes metabolism/synthesis for chemicals); T, transcription; TR, translocation.
( $P=0.052$ and $P=0.072$ respectively), indicating that there may be some disorder in the regulation of the TGF $\beta$ superfamily in the OGCs cultured in vitro.

Follicle development is accompanied by remodelling of the ECM, cytoskeleton and cell-to-cell junctions. Overall, $E_{2}$ treatment induced a reduction in the expression of actins, keratins and ECMs including types 1 and 4 collagen, laminin and integrin (Figs 3 and 4,
Supplementary Table 2). N-cadherin, JAM-A, afadin and cingulin are the main components of adherence junctions in mouse GCs and KRT8, characteristic of epithelial cell, in GCs decreases as follicles develop (Mora et al. 2012). We also detected these factors and the level of KRT8 expressed in GCs decreases with follicle development. Zalewski et al. (2012) reported that collagen type 4 was highly expressed in the follicle of

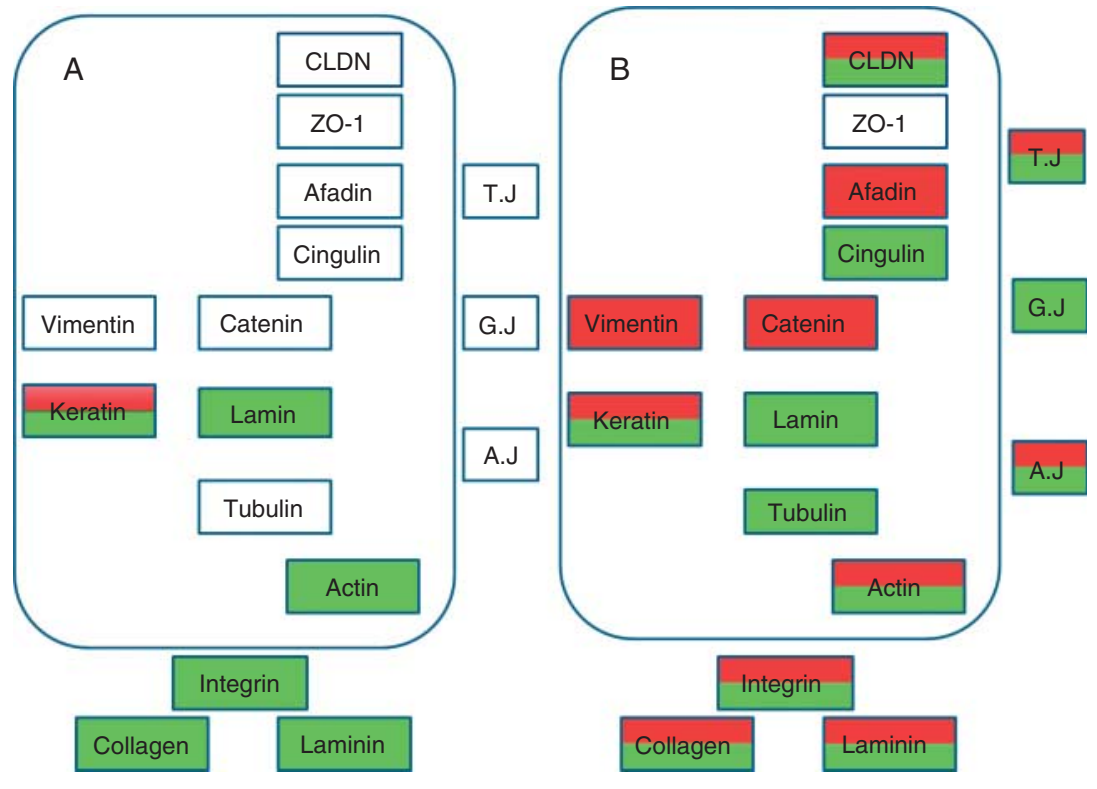

Figure 4 A schematic diagram of the expression of genes related to the cytoskeleton, cell-to-cell junctions and ECMs $(A)$ in $E_{2}(+)$ compared with $E_{2}(-)$ and $(B)$ in $A F$ compared with $E_{2}(+)$. Green, decrease; red, increase. T.J, tight junction; G.J, gap junction; A.J, adherence junction. 


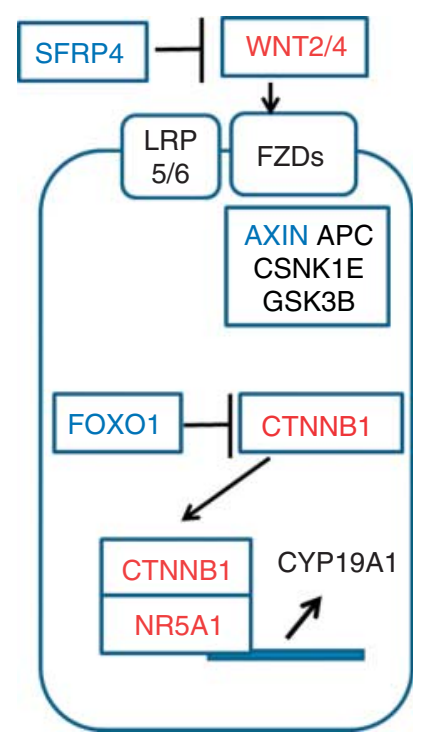

Figure 5 A schematic diagram of genes relate to WNT/CTNNB1 signalling in granulosa cells. The figure is created based on the previous reports (Boyer et al. 2010) and the Kegg pathway (http://www.genome. jp/kegg/pathway.html). SFRP4 prevents WNT molecule signalling by binding to WNT, WNT binds to the FZDs/LRP co-receptor, CTNNB1 is freed from the APC/CSNK1E/AXIN/GSK3B complex and translocates to the nucleus, where CTNNB1 binds to the transcription factor, NR5A1, which regulates CYP19A expression. FOXO1a inhibits CTNNB1 by binding to it.

estrogen receptor $\beta \mathrm{KO}$ mice, indicating a negative relationship between $\mathrm{E}_{2}$ and these ECMs. In addition, bovine expression of COL4A1, 2, 3, 4 and 5 has been reported to decrease as follicles increase in size (Rodgers et al. 1998). Furthermore, LAMA1, LAMB2 and LAMC1 are expressed in bovine follicular basal lamina of healthy antral follicles but have reduced expression in the atretic antral follicle (van Wezel et al. 1998). Rodgers et al. (2003), suggesting that decreased type 4 collagen and increased laminin are markers for healthy follicle development. Bovine GCs cultured on type 1 collagen gel exhibit a round shape and enhanced $E_{2}$ secretion (Huet et al. 2001). In this study, when OGCs formed antrum following 8 days of culture with $E_{2}$, the expression of COL4A1,COL4A2 and LAMB1 decreased. Taken together, regarding collagens and the cytoskeleton, OGCs cultured with $\mathrm{E}_{2}$ develop normally, but the opposing kinetics of laminin induce part of the OGCs to transition to atresia.

Oocytes in EAFs have great potential to yield embryos, but the ongoing in vitro culture system is not currently optimised to produce embryos with high efficiency. For example, in our preliminary experiment, the developmental ratio to the blastocyst stage was only $6.9 \%$ (12/174 OGCs) for oocytes grown in vitro whereas it was $30 \%$ for oocytes collected from medium antral follicles (3-6 $\mathrm{mm}$ in diameter). This result suggests that there were some abnormal events in current culture system for OGCs derived from EAFs. In addition, several genes deviated from normal gene expression profiles during long-time in vitro culture and these genes might be an important candidate to improve the current culture condition. This study shows that $E_{2}$ is a powerful supplement for in vitro development of OGCs, but other side effects should be considered because many parts of $E_{2}$ functions are categorised as cancer related (Supplementary Table 1).

In conclusion, this study demonstrates the significance of $E_{2}$ in the in vitro development of OGCs derived from EAFs. Developing OGCs have a specific gene expression profile that includes $E_{2}$ biosynthesis, and treatment of OGCs with $E_{2}$ impacts several genes to support the establishment of these gene expression profiles.

\section{Materials and Methods}

\section{Drugs and media}

Unless otherwise stated, all drugs were purchased from Sigma-Aldrich. TCM 199 medium was used for in vitro culture of OGCs (Gibco BRL) and was supplemented with $5.56 \mathrm{mM}$ glucose (final concentration, $11.2 \mathrm{mM}$ ), $0.1 \mathrm{mM}$ pyruvic acid, various concentrations of $E_{2}$ or androstenedione $\left(A_{4}\right)$, $0.02 \mathrm{mAU} / \mathrm{ml}$ FSH (Kawasaki Mitaka, Tokyo, Japan), 4\% polyvinylpyrrolidone (PVP) (360K), $4 \mathrm{mM}$ hypoxithantine and $10 \%$ FCS (5703H, ICN; Costa Mesa, CA, USA). Stock solution of $E_{2}$ and $A_{4}$ was prepared in ethanol at 1000-fold the required concentrations and the maximum ethanol concentration was never above $1 \mu \mathrm{l} / \mathrm{l}$. The TCM 199 medium used for the in vitro maturation (IVM) of oocytes contained 5\% FCS.

\section{Collection of ovaries and oocytes from EAFs}

Bovine ovaries were collected from a slaughterhouse and transported in PBS containing antibiotics, $10 \mathrm{mM}$ sucrose, $10 \mathrm{mM}$ glucose and $1 \mathrm{mM}$ pyruvic acid at $30{ }^{\circ} \mathrm{C}$ within $4 \mathrm{~h}$. Ovaries were wiped with $70 \%$ ethanol, the ovarian surface was sliced and EAFs (400-700 $\mu \mathrm{m}$ in diameter) were collected under a stereomicroscope using a scalpel in TCM 199 medium containing $3 \mathrm{mg} / \mathrm{ml} \mathrm{BSA}$. In our preliminary experiment, average diameter of oocytes in EAFs was $102.7 \pm 1.0 \mu \mathrm{m}$ (no. 92).

\section{Culture and IVM of OGCS}

OGCs were washed in culture medium, individually transferred to $200 \mu \mathrm{l}$ medium in a well (96-well plate, Becton Dickinson, Franklin Lakes, NJ, USA) and cultured for 16 days. Half of the medium was replaced with fresh medium and antrum formation was examined every 4 days (4, 8, 12 and 16 days in culture). After the culture period, OGCs having antra were subjected to IVM for $23 \mathrm{~h}$. After maturation, oocytes were denuded from surrounding cumulus cells and were fixed, permeabilised and mounted with antifade that contained 4'6-diamidino-2-phenylindole (DAPI) (Pro-long gold antifade reagent with DAPI; Invitrogen) on glass slides. The nuclear maturation was examined using a fluorescence digital microscope (BZ-8000; Keyence, Tokyo, Japan). 


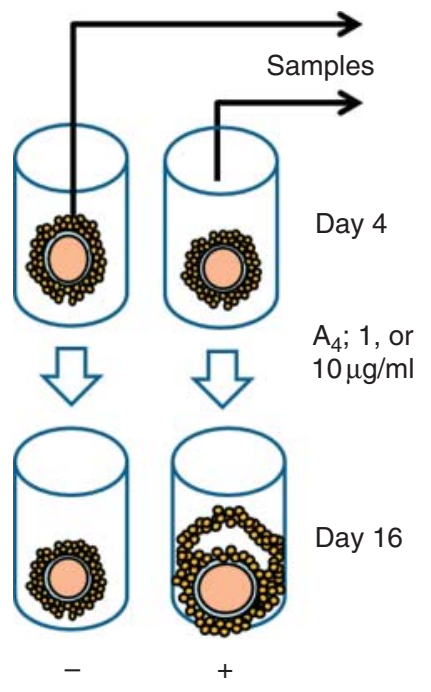

Determination of antrum formation

Figure 6 OGCs were cultured in 96-well plates with a single complex in each well. The medium was collected at day 4 before the OGCs formed antrum, and these OGCs were subsequently cultured for 12 days. At the end of culture period, OGCs were classified as OGCs having clear antrum (+) or OGCs having no antrum. The $E_{2}$ concentration in the medium was compared between competent $(+)$ and un-competent (-) OGCs.

\section{Estradiol concentration}

As described in the experimental design, the culture medium was sampled at day 4 of the in vitro culture period. The medium was stored at $-80^{\circ} \mathrm{C}$. The $\mathrm{E}_{2}$ concentration was measured using the $E_{2}$ immunoassay kit (DELFIA estradiol reagents, PerkinElmer, Waltham, MA, USA) according to the manufacturer's protocol. All measurements were conducted in one plate, and the coefficient of variation value was 1.36 .

\section{Gene expression analysis}

For the analysis of gene expression, total RNA was extracted from GCs of OGCs that had been exposed to no or $1 \mu \mathrm{g} / \mathrm{ml} \mathrm{E}_{2}$ for 4 days or OGCs that formed antrum at 8 days, using the RNAqueous Kit (Life Technologies Corp.) according to the manufacturer's protocol. RNA quality and quantity were assessed on a 2100 Bioanalyzer using the RNA 6000 Nano kit (Agilent Technologies, Palo Alto, CA, USA). Libraries were prepared from the samples using the TruSeq RNA Sample Preparation Kit (Illumina, Inc., San Diego, CA, USA), and the prepared samples were used to generate clusters on cBot (Illumina, Inc.). Two lanes per group were sequenced on a HisDefault 2000 (Illumina, Inc.) as 50 bp reads (single-read). The image analysis and basecalling were performed with CASAVA ver. 1.8.2 (Illumina, Inc.) according to the manufacturer's instructions. High-quality sequences (those passing the default quality-filtering parameters in the Illumina pipeline GERALD stage) were retained and aligned to the bovine genome sequence (bosTau6) and the exon-exon splice junction database downloaded from the UCSC sequence and annotation database (http://hgdownload.cse.ucsc.edu/ downloads.html\#cow). Both the raw and normalised (RPKM; Mortazavi et al. 2008) read counts were obtained using CASAVA and Genome Studio ver. 2011.1 (Illumina, Inc.). For the genes in which the normalised gene counts were $>1$, the fold-changes of the normalised counts between the groups were calculated. Statistical significance was assigned to each pairwise group comparison $\left(E_{2}(+): E_{2}(-), A F: E_{2}(+)\right.$ and $\mathrm{AF}: \mathrm{E}_{2}(-)$ groups) by setting up a Fisher's exact test, comparing the number of weighted, mapped reads for each gene to the total number of mapped reads for that group. Genes that were differentially expressed were interpreted in the context of their biological processes and functions and by their networks and pathways by Ingenuity Pathways Analysis (IPA; Ingenuity Systems, Inc., Redwood City, CA, USA). A detailed description of the method for performing IPA can be found at www. ingenuity.com. Fisher's exact test was used in the analysis of gene set enrichment in the functional categories.

\section{Experimental design}

Experiment 1

The effect of $E_{2}$ on the in vitro development of OGCs derived from EAFs was examined. OGCs were cultured in medium containing $0,0.1,1$ and $10 \mu \mathrm{g} / \mathrm{ml} \mathrm{E}_{2}$ for 16 days, and antrum formation was examined. Experiments were repeated ten times. In the first five trials, oocytes of OGCs having antrum were used to measure the diameter. In the last five trials, OGCs having antrum were subjected to IVM and nuclear maturation of the oocytes was examined.

\section{Experiment 2}

The effect of $\mathrm{A}_{4}$ on OGCs development, as well as the relationship between the $E_{2}$ concentration and the development of OGCs, was examined. As shown in Fig. 6, OGCs were

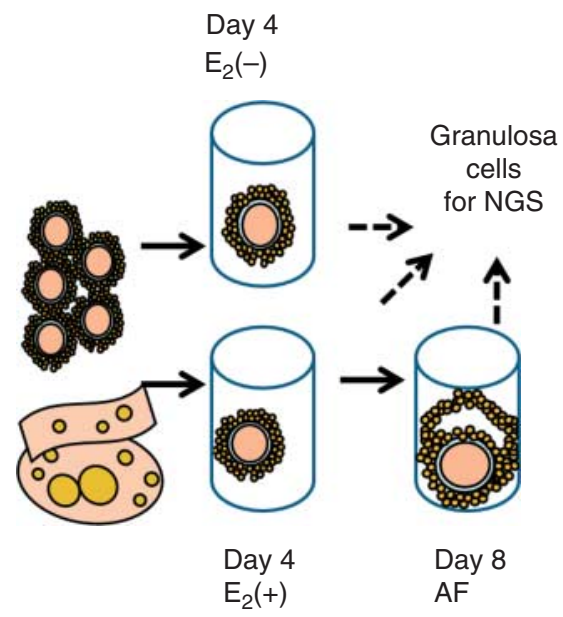

Figure 7 OGCs were collected from a donor cow and divided into two groups. OGCs were cultured in a 96-well plate individually. OGCs were cultured in medium containing no or $1 \mu \mathrm{g} / \mathrm{ml} E_{2}$ for 4 days, and granulosa cells were collected $\left(E_{2}(+)\right.$ and $E_{2}(-)$ group). AR group; OGCs were cultured for an additional 8 days in medium containing $1 \mu \mathrm{g} / \mathrm{ml} \mathrm{E}_{2}$ and granulosa cells were collected from OGCs forming antrum. 
cultured in medium containing 0,1 and $10 \mu \mathrm{g} / \mathrm{ml} \mathrm{A}_{4}$. At day 4 of the culture period, half of the culture medium was sampled and stored for later $E_{2}$ concentration measurement. At that time, no OGCs formed antrum. The OGCs were subsequently cultured for an additional 12 days. At the end of the culture period, OGCs were categorised as OGCs having antrum (competent OGCs) or OGCs having no antrum (un-competent OGCs). OGCs having antrum were further cultured in IVM medium, and the ratio of nuclear maturation was subsequently examined. Ten OGCs were used as replicates, and the experiment was repeated nine times. The $E_{2}$ concentration was measured from randomly selected medium samples, and the concentrations were compared between the competent and un-competent OGCs.

\section{Experiment 3}

The ability of fulvestrant to inhibit the effects of $E_{2}$ and $A_{4}$ on OGC development was examined. OGCs were cultured in medium containing either fulvestrant and $E_{2}$, or fulvestrant and $\mathrm{A}_{4}$ for 16 days, and antrum formation was examined. The combinations of fulvestrant and hormones were as follows: i) $\mathrm{A}_{4}, 1 \mu \mathrm{g} / \mathrm{ml}$ and $\mathrm{A}_{4}, 1 \mu \mathrm{g} / \mathrm{ml}+$ fulvestrant, $1 \mu \mathrm{g} / \mathrm{ml}$; ii) $\mathrm{E}_{2}$, $0.1 \mu \mathrm{g} / \mathrm{ml}$ and $E_{2}, 0.1 \mu \mathrm{g} / \mathrm{ml}+$ fulvestrant, $1 \mu \mathrm{g} / \mathrm{ml}$ and iii) $E_{2}$, $1 \mu \mathrm{g} / \mathrm{ml}$ and $E_{2}, 1 \mu \mathrm{g} / \mathrm{ml}+$ fulvestrant, $1 \mu \mathrm{g} / \mathrm{ml}$. This experiment was repeated ten times, and the ratio of antrum formation was compared between the hormone group and the hormone plus inhibitor group.

\section{Experiment 4}

The initial three experiments suggested that $E_{2}$ improves OGC development in vitro. In Experiment 4, we aimed to identify the molecular basis associated with the beneficial effect of $E_{2}$ on OGC development. As shown in Fig. 7, we collected 20 OGCs from a donor, and ten OGCs were cultured in medium containing 0 or $1 \mu \mathrm{g} / \mathrm{ml} \mathrm{E}_{2}$. At day 4 , three OGCs were randomly selected from the ten OGCs and GCs were collected from these three OGCs, which were defined as the $E_{2}(-)$ and $\mathrm{E}_{2}(+)$ groups respectively. Other OGCs were cultured in medium for an additional 4 days, and the antrum formation was examined. Antrum formation was observed in medium with $\mathrm{E}_{2}$ supplementation but no OGCs formed in the medium without $E_{2}$ supplementation. The GCs collected from the OGCs forming antra in medium containing $E_{2}$ were defined as AF groups. A total of 25 cows were used for these experiments, and GCs of the $E_{2}(-), E_{2}(+)$ and AF groups were collected from 75, 75 and 50 OGCs respectively. These GCs were subjected to comprehensive gene expression analysis.

\section{Statistical analysis}

The ratio of antrum formation and oocyte diameter was analysed by a one-way ANOVA followed by Tukey's post hoc test. The ratio of antrum formation was arcsin transformed before analysis. The nuclear maturations were compared using $\chi^{2}$ test. And the Bonferroni's method was used to adjust the $P$ values for multiple comparisons. $E_{2}$ concentrations were compared by a two-way ANOVA. $P$ values $<0.05$ were considered significant.

\section{Supplementary data}

This is linked to the online version of the paper at http://dx.doi. org/10.1530/REP-12-0319.

\section{Declaration of interest}

The authors declare that there is no conflict of interest that could be perceived as prejudicing the impartiality of the research reported.

\section{Funding}

This study was supported by the Ministry of Education, Culture, Sports, Science and Technology (MEXT) supported program for the Strategic Research Foundation at Private Universities (S0801025).

\section{Acknowledgements}

The authors thank Yuh Shiwa, Misaki Imai, Hikaru Wada, Chihiro Yamamoto and Kazuma Tsunematsu for technical support.

\section{References}

Bonnet A, Bevilacqua C, Benne F, Bodin L, Cotinot C, Liaubet L, Sancristobal M, Sarry J, Terenina E, Martin P et al. 2011 Transcriptome profiling of sheep granulosa cells and oocytes during early follicular development obtained by laser capture microdissection. BMC Genomics 18 12-417. (doi:10.1186/1471-2164-12-417)

Boyer A, Goff AK \& Boerboom D 2010 WNT signaling in ovarian follicle biology and tumorigenesis. Trends in Endocrinology and Metabolism 21 25-32. (doi:10.1016/j.tem.2009.08.005)

Bridges PJ, Brusie MA \& Fortune JE 2005 Elevated temperature (heat stress) in vitro reduces androstenedione and estradiol and increases progesterone secretion by follicular cells from bovine dominant follicles. Domestic Animal Endocrinology 29 508-522. (doi:10.1016/j.domaniend.2005.02.017)

Couse JF, Yates MM, Deroo BJ \& Korach KS 2005 Estrogen receptor- $\beta$ is critical to granulosa cell differentiation and the ovulatory response to gonadotropins. Endocrinology 146 3247-3262. (doi:10.1210/en.20050213)

Drummond AE 2006 The role of steroids in follicular growth. Reproductive Biology and Endocrinology 10 4-16. (doi:10.1186/1477-7827-4-16)

Emmen JM, Couse JF, Elmore SA, Yates MM, Kissling GE \& Korach KS 2005 In vitro growth and ovulation of follicles from ovaries of estrogen receptor $(E R)\{\alpha\}$ and $E R\{\beta\}$ null mice indicate a role for $\operatorname{ER}\{\beta\}$ in follicular maturation. Endocrinology 146 2817-2826. (doi:10.1210/en.20041108)

Fenwick MA, Mansour YT, Franks S \& Hardy K 2011 Identification and regulation of bone morphogenetic protein antagonists associated with preantral follicle development in the ovary. Endocrinology 152 3515-3526. (doi:10.1210/en.2011-0229)

Garside SA, Harlow CR, Hillier SG, Fraser HM \& Thomas FH 2010 Thrombospondin-1 inhibits angiogenesis and promotes follicular atresia in a novel in vitro angiogenesis assay. Endocrinology 151 1280-1289. (doi:10.1210/en.2009-0686)

Green MP, Ledgard AM, Beaumont SE, Berg MC, McNatty KP, Peterson AJ \& Back PJ 2011 Long-term alteration of follicular steroid concentrations in relation to subclinical endometritis in postpartum dairy cows. Journal of Animal Science 89 3551-3560. (doi:10.2527/jas.2011-3958)

Greenaway J, Gentry PA, Feige JJ, LaMarre J \& Petrik JJ 2005 Thrombospondin and vascular endothelial growth factor are cyclically expressed in an inverse pattern during bovine ovarian follicle development. Biology of Reproduction 72 1071-1078. (doi:10.1095/ biolreprod.104.031120) 
Harlow CR, Bradshaw AC, Rae MT, Shearer KD \& Hillier SG 2007 Oestrogen formation and connective tissue growth factor expression in rat granulosa cells. Journal of Endocrinology 192 41-52. (doi:10.1677/ joe.1.06689)

Hayashi KG, Ushizawa K, Hosoe M \& Takahashi T 2010 Differential genome-wide gene expression profiling of bovine largest and secondlargest follicles: identification of genes associated with growth of dominant follicles. Reproductive Biology and Endocrinology 5 8-11. (doi:10.1186/1477-7827-8-11)

Hirao Y, Itoh T, Shimizu M, Iga K, Aoyagi K, Kobayashi M, Kacchi M, Hoshi H \& Takenouchi N 2004 In vitro growth and development of bovine oocyte-granulosa cell complexes on the flat substratum: effects of high polyvinylpyrrolidone concentration in culture medium. Biology of Reproduction 70 83-91. (doi:10.1095/biolreprod.103.021238)

Huet C, Pisselet C, Mandon-Pépin B, Monget P \& Monniaux D 2001 Extracellular matrix regulates ovine granulosa cell survival, proliferation and steroidogenesis: relationships between cell shape and function. Journal of Endocrinology 169 347-360. (doi:10.1677/joe.0.1690347)

Huynh K, Jones G, Thouas G, Britt KL, Simpson ER \& Jones ME 2004 Estrogen is not directly required for oocyte developmental competence. Biology of Reproduction 70 1263-1269. (doi:10.1095/biolreprod.103.022111)

Kimelman D \& Xu W $2006 \beta$-Catenin destruction complex: insights and questions from a structural perspective. Oncogene 25 7482-7491. (doi:10.1038/sj.onc.1210055)

Knight PG \& Glister C 2006 TGF- $\beta$ superfamily members and ovarian follicle development. Reproduction 132 191-206. (doi:10.1530/rep.1.01074)

Le Bellego F, Pisselet C, Huet C, Monget P \& Monniaux D 2002 Laminina6ß1 integrin interaction enhances survival and proliferation and modulates steroidogenesis of ovine granulosa cells. Journal of Endocrinology 172 45-59. (doi:10.1677/joe.0.1720045)

Mann GE \& Lamming GE 2001 Relationship between maternal endocrine environment, early embryo development and inhibition of the luteolytic mechanism in cows. Reproduction 121 175-180. (doi:10.1530/rep.0. 1210175)

Mingoti GZ, Garcia JM \& Rosa-e-Silva AA 2002 Steroidogenesis in cumulus cells of bovine cumulus-oocyte-complexes matured in vitro with BSA and different concentrations of steroids. Animal Reproduction Science 69 175-186. (doi:10.1016/S0378-4320(01)00187-7)

Monniaux D, Clemente N, Touzé JL, Belville C, Rico C, Bontoux M, Picard JY \& Fabre S 2008 Intrafollicular steroids and anti-Müllerian hormone during normal and cystic ovarian follicular development in the cow. Biology of Reproduction 79 387-396. (doi:10.1095/biolreprod. 107.065847)

Mora JM, Fenwick MA, Castle L, Baithun M, Ryder TA, Mobberley M, Carzaniga R, Franks S \& Hardy K 2012 Characterization and significance of adhesion and junction-related proteins in mouse ovarian follicles. Biology of Reproduction 86 1-14. (doi:10.1095/biolreprod.111.096156)

Mortazavi A, Williams BA, McCue K, Schaeffer L \& Wold B 2008 Mapping and quantifying mammalian transcriptomes by RNA-Seq. Nature Methods 5 621-628. (doi:10.1038/nmeth.1226)

Nagashima T, Kim J, Li Q, Lydon JP, DeMayo FJ, Lyons KM \& Matzuk MM 2011 Connective tissue growth factor is required for normal follicle development and ovulation. Molecular Endocrinology 25 1740-1759. (doi:10.1210/me.2011-1045)

Nilsson EE, Doraiswamy V \& Skinner MK 2003 Transforming growth factor$\beta$ isoform expression during bovine ovarian antral follicle development. Molecular Reproduction and Development 66 237-246. (doi:10.1002/ mrd.10350)

Nishimoto H, Hamano S, Hill GA, Miyamoto A \& Tetsuka M 2009 Classification of bovine follicles based on the concentrations of steroids, glucose and lactate in follicular fluid and the status of accompanying follicles. Journal of Reproduction and Development 55 219-224. (doi:10.1262/jrd.20114)

Okutsu Y, Itoh MT, Takahashi N \& Ishizuka B 2010 Exogenous androstenedione induces formation of follicular cysts and premature luteinization of granulosa cells in the ovary. Fertility and Sterility 93 927-935. (doi:10.1016/j.fertnstert.2008.10.064)
Ouellette Y, Price CA \& Carrière PD 2005 Follicular fluid concentration of transforming growth factor- $\beta 1$ is negatively correlated with estradiol and follicle size at the early stage of development of the first-wave cohort of bovine ovarian follicles. Domestic Animal Endocrinology 29 623-633. (doi:10.1016/j.domaniend.2005.04.008)

Parakh TN, Hernandez JA, Grammer JC, Weck J, Hunzicker-Dunn M, Zeleznik AJ \& Nilson JH 2006 Follicle-stimulating hormone/cAMP regulation of aromatase gene expression requires $\beta$-catenin. PNAS 103 12435-12440. (doi:10.1073/pnas.0603006103)

Rodgers HF, Irvine CM, van Wezel IL, Lavranos TC, Luck MR, Sado Y, Ninomiya Y \& Rodgers RJ 1998 Distribution of the $\alpha 1$ to $\alpha 6$ chains of type IV collagen in bovine follicles. Biology of Reproduction 59 1334-1341. (doi:10.1095/biolreprod59.6.1334)

Rodgers RJ, Irving-Rodgers HF \& Russell DL 2003 Extracellular matrix of the developing ovarian follicle. Reproduction 126 415-424. (doi:10.1530/rep.0.1260415)

Romero S \& Smitz J 2010 Exposing cultured mouse ovarian follicles under increased gonadotropin tonus to aromatizable androgens influences the steroid balance and reduces oocyte meiotic capacity. Endocrine 38 243-253. (doi:10.1007/s12020-010-9380-y)

Rosales-Torres AM, Alonso I, Vergara M, Romano MC, Castillo-Juárez $\mathbf{H}$, Avalos A, Rosado A \& Gutiérrez CG 2010 Vascular endothelial growth factor isoforms 120, 164 and 205 are reduced with atresia in ovarian follicles of sheep. Animal Reproduction Science 122 111-117. (doi:10.1016/j.anireprosci.2010.08.002)

Taketsuru H, Hirao Y, Takenouchi N, Iga K \& Miyano T 2011 Effect of androstenedione on the growth and meiotic competence of bovine oocytes from early antral follicles. Zygote 9 1-9. (doi:10.1017/ so967199411000268)

Tesfaye D, Ghanem N, Carter F, Fair T, Sirard MA, Hoelker M, Schellander K \& Lonergan P 2009 Gene expression profile of cumulus cells derived from cumulus-oocyte complexes matured either in vivo or in vitro. Reproduction, Fertility, and Development 21 451-461. (doi:10.1071/RD08190)

Walters KA, Allan CM \& Handelsman DJ 2008 Androgen actions and the ovary. Biology of Reproduction 78 380-389. (doi:10.1095/biolreprod. 107.064089)

Wang HX, Li TY \& Kidder GM 2010 WNT2 regulates DNA synthesis in mouse granulosa cells through $\beta$-catenin. Biology of Reproduction $\mathbf{8 2}$ 865-875. (doi:10.1095/biolreprod.109.080903)

Wang HX, Tekpetey FR \& Kidder GM 2009 Identification of WNT/ beta-CATENIN signaling pathway components in human cumulus cells. Molecular and Human Reproduction 15 11-17. (doi:10.1093/molehr/ gan070)

West-Farrell ER, Xu M, Gomberg MA, Chow YH, Woodruff TK \& Shea LD 2009 The mouse follicle microenvironment regulates antrum formation and steroid production: alterations in gene expression profiles. Biology of Reproduction 80 432-439. (doi:10.1095/biolreprod.108.071142)

van Wezel IL, Rodgers HF \& Rodgers RJ 1998 Differential localization of laminin chains in bovine follicles. Journal of Reproduction and Fertility 112 267-278. (doi:10.1530/jrf.0.1120267)

Xu M, West E, Shea LD \& Woodruff TK 2006 Identification of a stage-specific permissive in vitro culture environment for follicle growth and oocyte development. Biology of Reproduction 75 916-923. (doi:10.1095/biolreprod.106.054833)

Zalewski A, Cecchini EL \& Deroo BJ 2012 Expression of extracellular matrix components is disrupted in the immature and adult estrogen receptor $\beta$-null mouse ovary. PLOS ONE 7 e29937. (doi:10.1371/journal.pone. 0029937)

Received 17 August 2012

First decision 28 September 2012

Revised manuscript received 20 October 2012

Accepted 2 November 2012 